\title{
Reformas educativas, formação e subjectividades dos professores"
}

Fernando Ilídio Ferreira

Universidade do Minho, Instituto de Estudos da Criança

\section{Introdução}

A formação contínua de professores teve forte incremento, em Portugal, no contexto das reformas educativas iniciadas nos anos de 1980, em consequência dos financiamentos avultados provenientes da União Europeia e de uma lógica de oferta e procura induzida por um enquadramento legal que estabeleceu a ligação entre a formação e a progressão na carreira. Entre outros normativos legais, salientam-se a publicação da Lei de Bases do Sistema Educativo, em 1986 (lei n. 46/86), do Ordenamento Jurídico da Formação Inicial e Contínua de Professores e Educadores de Infância (decreto-lei n. 344/89), do Estatuto da Carreira Docente (decreto-lei n. 139-A/90) e do próprio Regime Jurídico da Formação Contínua de Professores e Educadores (decreto-lei n. 249/92), tendo este último instituído mecanismos de acreditação e creditação das acções de formação articulados directamente com a

\footnotetext{
* Foi mantida a ortografia de Portugal
}

progressão na carreira dos professores. Para estes, a frequência de acções de formação e a obtenção dos créditos correspondentes passaram a constituir uma condição obrigatória para a progressão na carreira e, como tal, conduziram a um aumento exponencial da oferta e da procura, numa lógica predominantemente individual e instrumental (Ferreira, 1998).

Esse enquadramento jurídico-administrativo conduziu ao aparecimento de novas entidades formadoras a partir de 1993, nomeadamente os centros de formação de associações de escolas e os centros de formação de associações de professores. Contudo, já antes eram visíveis preocupações com a formação contínua, especialmente a seguir ao 25 de abril de 1974, num contexto de mobilização associativa e sindical e também das próprias escolas. Na década de 1980, diversas entidades promoveram acções de formação contínua em modalidades não formais, sem vinculação à progressão na carreira, mas obtendo adesão voluntária dos professores. Destaca-se o papel das instituições de ensino superior, dos sindicatos e de outras associações profissionais e dos serviços centrais e regionais do Ministério da Educação, que intervie- 
ram principalmente no âmbito do ensino primário. Da parte desses últimos, as acções de formação eram realizadas de forma directa ou por meio de programas nacionais, como o Programa Interministerial de Promoção do Sucesso Educativo (PIPSE). Por sua vez, os sindicatos e associações profissionais e pedagógicas assumiam nesse período um importante papel de mobilização dos professores para acções de informação e sensibilização, com um carácter de dinamização pedagógica e laboral.

$\mathrm{Na}$ altura em que foi instituído o sistema formal de formação contínua, era mesmo no interior do associativismo sindical e profissional que se verificava maior apetência para a organização de acções de formação, em modalidades de encontros, jornadas, seminários, conferências e outros; esse campo de intervenção era percebido por seus promotores como uma forma de crescimento e afirmação das próprias estruturas sindicais e associativas junto dos professores e da opinião pública em geral. Em grande medida, as iniciativas de formação contínua que eram levadas a efeito pelas diversas entidades assumiam carácter de "actualização" dos professores, eram de frequência voluntária, tinham carácter pontual e de curta duração e eram realizadas frequentemente na forma de "jornadas pedagógicas" no início de cada ano lectivo.

Como se disse, foi com o enquadramento normativo-legal dos anos de 1980/1990 e com os financiamentos provenientes da União Europeia concretamente no âmbito do Programa de Desenvolvimento Educativo para Portugal (PRODEP) que a formação contínua adquiriu os contornos que tem actualmente, obtendo forte incremento em termos quantitativos. Todavia, neste artigo defende-se que esse incremento não teve equivalente na transformação das concepções e práticas de formação, gerando até lógicas contrárias aos pressupostos participativos e emancipatórios da educação de adultos. Apesar de tratar-se de um campo de formação profissional de adultos, a formação contínua desenvolveu-se predominantemente à imagem do modelo formal de escolarização e com influências de lógicas de racionalização das reformas educativas. Nas primeiras secções do artigo abordam-se essas ló- gicas, salientando-se seus efeitos nas subjectividades dos professores. Seguidamente, abordam-se algumas concepções alternativas, encarando a formação contínua de professores numa perspectiva de educação de adultos e supondo, assim, outro tipo de relação dos professores com a formação e entre esta e os contextos e situações reais de trabalho.

\section{As reformas educativas e os seus efeitos nas subjectividades dos professores}

As tentativas de resposta às profundas transformações e crise dos sistemas educativos emergentes nos anos de 1960/1970 assentaram, num primeiro momento, na utilização pelo Estado de instrumentos de macroplanificação, do tipo das grandes reformas educativas. Tendo verificado o esgotamento desse modelo, num segundo momento o Estado deu primazia a mecanismos de microrregulação, apelando à responsabilidade da sociedade civil e à procura de soluções locais para os problemas cada vez mais complexos e difíceis de resolver à escala nacional. É nesse período que se confrontam diferentes propostas e orientações, por vezes de compatibilização problemática, ao nível das políticas e da acção educativas, como é o caso da democratização, da modernização e do neoliberalismo (Lima \& Afonso, 2002). No nosso país, por exemplo, em nenhum dos momentos referidos o Estado abandonou a lógica de reforma de pendor centralista e burocrático, orientada para a racionalização e o controlo, embora tenha transposto para o campo da educação e formação, sobretudo no plano retórico, uma racionalidade produtiva e competitiva, de inspiração neoliberal. Focalizada essencialmente nos resultados, do que é exemplo o interesse pelos rankings das escolas, essa racionalidade tem-se ancorado em noções como eficácia, eficiência, qualidade etc., as quais passaram a fazer parte do discurso político não apenas em referência ao sector empresarial mas também a outros sectores da acção pública, incluindo a educação e a formação.

Com efeito, a partir da década de 1980, as ideias de descentralização, participação e autonomia e os inerentes apelos aos dinamismos locais surgiram em 
resposta às críticas ao centralismo e à burocratização do Estado, à reprodução das desigualdades e a outras críticas que durante os anos de 1960/1970 tiveram como alvo as instituições em geral e em particular a escola. O local - o espaço local, os actores locais, as iniciativas locais - tornou-se o horizonte privilegiado do discurso e das políticas educativas (Ferreira, 2005). Porém, a tão proclamada devolução de poderes ao local não se traduziu de forma linear, como é entendido e sugerido frequentemente, num reforço do princípio da comunidade em detrimento dos princípios do Estado e do mercado. O mesmo fenómeno abriu caminho à propagação de políticas neoliberais, ora de modo mais explícito nalguns países, ora de um modo mais difuso noutros.

Embora a visibilidade das políticas neoliberais não seja a mesma em todos os países, é necessário ter em conta que essa difusão não se verifica apenas em termos de políticas concretas; ela manifesta-se igualmente no plano das subjectividades e dos valores. Assim, os valores empresariais e mercantis - da produtividade, da competição e do lucro - invadiram não apenas o sector económico como também outros domínios da organização social. O próprio sector da administração pública foi influenciado por esses valores, difundindo-se a ideia de que ele é ineficiente e que a lógica de mercado e o modelo de funcionamento da empresa constituem a chave da sua modernização e eficácia.

No campo educativo, a lógica neoliberal tem sido caracterizada por um conjunto de ideias que fazem apelo à "eficiência", à "eficácia", à "excelência", à "qualidade", à "escolha da escola pelos pais" etc., revelando uma focalização das políticas educativas, designadamente das políticas de autonomia e gestão local da escola, nos direitos do consumidor mais do que nos direitos do cidadão (Whitty, 1996). Considerando, no entanto, que no campo da educação e das políticas sociais em geral as forças de mercado continuam a ser mediadas pelo Estado, alguns autores sustentam que, nesse caso, não se pode falar num mercado propriamente dito, mas num "quase-mercado". Segundo Geoff Whitty, essas políticas de quase-mercado não constituem uma privatização do sistema educativo num sentido estritamente económico; todavia, elas requerem que as instituições do sector público operem similarmente às instituições do sector privado.

Os analistas sociais têm-se pronunciado de diferentes modos sobre esses fenómenos, tendo em conta a maior ou menor intensidade com que a lógica neoliberal se tem manifestado, tratando-se de países centrais, periféricos ou semiperiféricos, como é o caso de Portugal. Entre nós, e tomando como referência o período que vai de meados da década de 1980 a meados da década de 1990, Lima e Afonso (2002) sustentam que os vectores da democratização, da modernização e do neoliberalismo se manifestaram de modo particular, considerando que as reformas neoliberais tiveram uma expressão híbrida, mitigada ou até, em alguns casos, em contra-ciclo, distinguindo-se, em muitos aspectos, da agenda emergente no contexto internacional.

Num estudo sobre as políticas educativas em Portugal, Almerindo Afonso (1998) concluiu que, apesar de se encontrarem vectores do gerencialismo neoliberal ao nível mais geral da definição das políticas públicas, eles não se traduziram de forma tão clara em termos de orientações concretas para a gestão das escolas. Considera, por isso, que não é possível falar, no caso do nosso país, de uma valorização mais do que retórica da ideologia do mercado no domínio da educação pública, tratando-se, pois, de um "neoliberalismo educacional mitigado". No mesmo sentido, Manuel Sarmento (1999) sustenta que algumas das medidas mais marcantes das políticas neoliberais do mundo anglosaxónico não têm expressão visível no caso português senão em termos simbólicos. Argumenta, aliás, que o que é mais específico no nosso país é a existência de um "tempo em contra-ciclo", correspondente ao processo escolar pós- 25 de abril, considerando que esse período foi marcado por fenómenos aparentemente contraditórios: a expansão da escola básica é norteada pelos princípios da democratização e da igualdade de oportunidades, embora ocorra num momento em que noutros países se verificava já uma contracção do financiamento dos sistemas educativos e se afirmava, em nível global, a ideologia neoliberal. 
No entanto, outros analistas têm vindo chamar a atenção para o facto de que os valores neoliberais circulam hoje à escala mundial, entre os sectores económico, social, político e cultural, para o que muito contribui a grande mobilidade das pessoas e da informação, assegurada predominantemente pelas tecnologias da informação e comunicação, as revistas e livros, as conferências e encontros, as associações profissionais e científicas, os especialistas e as organizações internacionais. Ora, esses elementos fazem parte de uma "circulação 'internacional' de ideias sobre práticas apropriadas e interpretações da mudança escolar" (Popkewitz, 2000, p. 48). Por meio de isomorfismos, como explica John Meyer (2000), a sociedade global fornece modelos que influenciam bastante os sistemas educativos nacionais. E, se existe uma cultura educacional global e um emergente sistema educativo global, eles não podem ser concebidos como resultado apenas de uma espécie de aproximação de práticas. Há certamente uma influência global generalizada, mas esta não decorre do domínio de uns países sobre outros; resulta, sobretudo, do facto de o sistema educativo globalizado envolver uma densa estrutura de associações e profissões educacionais, e de outros sistemas de prestígio, chamando a atenção para "histórias educacionais de sucesso".

As reformas neoliberais correspondem, assim, a um fenómeno de alcance global, que, não obstante as especificidades contextuais, se propaga por meio de um "espírito gestionário" (Ogien, 1995). Ainda que a lógica neoliberal não tenha atingido a mesma expressão em todos os países, não podem ser ignorados seus efeitos profundos, sobretudo no plano dos valores e das subjectividades, na medida em que ela se manifesta quer por um "neoliberalismo doutrinário" - como é mais o caso da Grã-Bretanha -, quer por um "neoliberalismo gestionário" - como é o caso de outros países da Europa (Jobert, 1994). Há que levar em conta, portanto, as formas de penetração difusa da orientação neoliberal e sua difusão subterrânea à escala local, pois, como sustentam Ball e Van Zanten (1998), o processo nacional de elaboração de políticas é um processo de bricolage e, nesse sentido, as reformas e as políticas neoliberais, sejam elas entendidas como manifestações "objectivas" ou como tecnologias de circulação e difusão de ideias e de valores e de impregnação das subjectividades dos professores e de outros actores educativos, devem ser compreendidas como o produto de múltiplas influências e interdependências (Ball, 1994).

De acordo com Stephen Ball (2002), as tecnologias políticas de reforma educacional não são apenas veículos para a mudança técnica e estrutural; são também mecanismos que contribuem para a mudança das subjectividades, das identidades e dos valores. Sob a aparência de liberdade que é criada pela retórica da devolução de poderes ao local, da flexibilidade e autonomia, emergem novas formas de controlo que penetram as subjectividades dos professores. Por exemplo, as tecnologias políticas de reforma educativa, das quais o autor destaca o mercado, o gerencialismo e, particularmente, a performatividade, põem em causa a colegialidade e a autenticidade dos professores. A nova cultura da performatividade competitiva gera sentimentos de culpa, incerteza e insegurança ontológica: "estarei a trabalhar bem?", "estarei a trabalhar o suficiente?", "estarei a trabalhar no sentido certo?", “será isto que querem que eu faça?". Ora, essa insegurança tende a gerar uma "fantasia encenada" para ser vista e avaliada; o espectáculo e a opacidade tendem a sobrepor-se à transparência e à autenticidade.

Nosso país, como se disse, tem características específicas, mas isso não significa que seja imune a essas influências globais. O que acontece é que, entre nós, as ideias de produtividade e competitividade, de inspiração empresarial e mercantil, se têm manifestado de modo peculiar, surgindo à mistura com políticas e práticas que se mantêm fortemente centralizadas e burocráticas. Isto é, poder-se-ia pensar que a criação de centros de formação de associação de escolas, de territórios educativos de intervenção prioritária, de agrupamentos de escolas etc., no quadro das políticas ditas de descentralização, territorialização e autonomia, conduziriam ao fim do centralismo burocrático; no entanto, o que se tem observado é sobretudo uma contradição entre os discursos difundidos por especia- 
listas da educação e por líderes políticos e administrativos - imbuídos de uma retórica de descentralização, territorialização, contratualização, autonomia, flexibilidade etc. - e as práticas centralizadas e burocráticas que não deixaram nunca de estar presentes, sendo hoje visíveis também no plano local. É que essas práticas, enquanto fenómeno estrutural e cultural, não dizem respeito apenas ao Estado e à administração central e ao tipo de relações que esses actores mantém com os actores locais, sejam o município, os agrupamentos de escolas, os centros de formação ou outros. Em grande medida, são os próprios actores locais que promovem hoje objectivos e mobilizam recursos e metodologias que não diferem, no essencial, dos utilizados à escala nacional-estatal, constatando-se mesmo, em alguns casos, que o centralismo burocrático se reproduz à escala local com maior afinco do que foi ou é utilizado à escala nacional.

\section{A formação de professores e o papel das instituições de ensino superior}

A formação de professores está intimamente relacionada a um fenómeno que alguns autores têm designado como universitarização ou academização da formação, decorrente da passagem da formação de professores para as universidades e outras instituições de ensino superior. João Formosinho (2002) considera que esse fenómeno introduziu benefícios, designadamente uma fundamentação teórica mais sólida da acção educativa; a valorização do estatuto da profissão docente; mais investigação em vários domínios das ciências da educação; mais investigação sobre o ensino, os professores e as escolas; o alargamento de perspectivas profissionais dos professores; a emergência de projectos de investigação e intervenção e uma maior aproximação das universidades e dos seus docentes e investigadores às realidades dos outros níveis de ensino. No entanto, salienta que o fenómeno de academização da formação gerou outros efeitos, associados às características institucionais e organizacionais da universidade tradicional: dizem respeito à compartimentação disciplinar, à fragmen- tação feudal do poder centrada em territórios de base disciplinar, ao individualismo competitivo que resiste a uma coordenação docente, sendo, então, incongruentes com o próprio discurso académico corrente, que advoga, relativamente à formação de professores e à actividade educativa nas escolas, o trabalho em equipa, a coordenação docente e a colegialidade, a interdisciplinaridade e a integração curricular, a integração comunitária da escola etc.

É necessário sublinhar que a academização da formação ocorre por essa via institucional e organizacional mas também pelo contacto dos professores de outros níveis de ensino com a cultura universitária. Em resultado dos programas de formação de que participam, os professores tendem a reproduzir discursos teoricamente elaborados, mas que, em vez de contribuírem para a reflexão sobre as próprias práticas, tendem a gerar efeitos de sua ocultação. Em contrapartida, no que concerne à investigação, os académicos têm incidido seus estudos principalmente sobre as políticas, as práticas e os contextos dos outros níveis de ensino, mantendo ausentes análise e reflexão crítica sobre suas próprias práticas e sobre a cultura universitária em que se inserem.

Ademais, sem vinculação aos contextos e situações reais de trabalho, a própria teoria tende a ser confundida com retórica. O discurso académico, tal como outros discursos que proliferam no campo educativo, tende a gerar uma inflação retórica que, em vez de estimular o desenvolvimento de práticas profissionais reflexivas, pode estar a acentuar a referida azáfama de mudança nas escolas. A esse respeito, a análise de António Nóvoa (1999) sobre a situação actual dos professores é bastante elucidativa: observa-se um excesso ao nível da retórica política e dos mass-media, das linguagens dos especialistas internacionais, do discurso científico educacional, das "vozes" individuais dos professores e, simultaneamente, uma pobreza ao nível das políticas educativas, dos programas da formação de professores, das práticas pedagógicas e das práticas associativas docentes. O período recente tem sido marcado, como diz, pelo "excesso de discursos", pela "pobreza das práticas" e por um pensamento que 
se projecta num "excesso de futuro" como forma de justificar um "défice de presente". Consequentemente, a mudança tende a ser encarada como um mero jogo nominalista, como se não houvesse outra mudança para além da alteração dos nomes.

Em vez de contrariar esse entendimento da mudança, as instituições de formação de professores podem estar a acentuá-lo, se não promoverem um pensamento reflexivo, crítico e comprometido com os contextos de acção concreta. Isso implica uma mudança de atitude das instituições de ensino superior, dos académicos e investigadores relativamente às formas de apoio às escolas. Rui Canário (2002) sublinha que a maior parte dos processos de inovação e reforma dos últimos 30 anos foram da iniciativa central e desenvolveram-se numa lógica estreita de tutela, concebendo o papel da administração fundamentalmente como um processo de ensinar as escolas e os professores a serem inovadores e criativos.

Esse autor defende, no entanto, que a maior exigência que se coloca às entidades que pretendem realizar um "apoio externo crítico às escolas" é a adopção de uma atitude de grande humildade, de modo que se possa aprender com elas. Desse modo, não se trata de ensinar as escolas a serem criativas e inovadoras, mas de realizar com elas um processo de aprendizagem a partir do que elas produzem. Mas para que isso seja possível, conclui Rui Canário, é necessário criar condições para dar a palavra às escolas e aprender a escutá-las.

\section{Concepções da formação contínua de professores como educação de adultos}

Como se referiu anteriormente, o sistema formal de formação contínua de professores que vigora entre nós é fruto de um longo processo de discussão política, sindical e académica e de produção legislativa. Houve um factor que norteou todo o processo: o entendimento da formação contínua como condição obrigatória para a progressão na carreira. Embora nem toda a formação tenha passado a realizar-se no âmbito desse sistema formal e a obedecer a essa ligação tão estreita entre formação e carreira, ela introduziu novas linguagens, práticas e subjectividades e uma clara orientação para a racionalização e formalização dos processos organizacionais e pedagógicos. Isso porque o sistema formal instituído exigiu a definição de um enquadramento jurídico, o qual recorreu a um conjunto de noções administrativo-formais tais como créditos, creditação e acreditação; áreas, modalidades e níveis; avaliação e certificação; competências e estatutos; direitos e deveres; coordenação e inspecção; verbas, receitas, financiamento e outros.

Do ponto de vista organizacional, vários constrangimentos decorrem dessa ligação da formação contínua à progressão na carreira e do sistema obrigatório $\mathrm{e}$ industrializado que essa ligação gerou. Mas decorrem igualmente do pressuposto tecnocrático da divisão social do trabalho da formação: de um lado os gestores, decisores, planificadores e formadores; do outro, os "formandos" que "frequentam" as acções de formação. Isto é: de um lado os que definem prioridades, necessidades, cursos e programas de formação; do outro, os "carenciados" da formação. Ora, essas lógicas estão de tal modo enraizadas que são defendidas não apenas por quem as concebe ao nível do sistema como também pelos próprios actores locais, incluindo os professores "formandos". Além disso, tendem a sobrepor-se ou a confundir-se, na prática, com o próprio conceito de formação contínua, em resultado da proliferação daquelas noções administrativo-formais e da linguagem bancária e contabilística utilizada.

Essas lógicas têm implicações pedagógicas na formação, na medida em que os professores tendem a ser encarados como formandos-alunos e não como adultos e profissionais sujeitos e autores da sua própria formação. Estabelecendo, por um lado, a separação entre funções de concepção e de execução e, por outro lado, a separação entre espaços e tempos da formação e espaços e tempos do trabalho, não propiciam a autoformação e a aprendizagem colectiva entre pares, em modalidades de interformação e ecoformação. É igualmente essa separação que está na origem da terminologia do "dar" e "receber" formação, muito utilizada pelos agentes da formação. Mesmo as designadas "novas formas de organização do trabalho" e "novas 
modalidades de formação", que apelam a uma maior flexibilidade e autonomia e supõem maior articulação entre trabalho e formação, estão imbuídas de uma lógica individual-instrumental, pois a oferta e a procura de acções de formação contínua tornou-se instrumental em relação às carreiras individuais dos professores, tornando assim difícil a contextualização da formação nas escolas e nos seus projectos. Em grande medida, as novas modalidades de organização do trabalho e da formação filiam-se ao "modelo da competência" e da "carteira de competências", baseado numa lógica de acumulação, por conta própria, de um "capital" - os créditos de formação, acumuláveis ou capitalizáveis. Ora, ao assentar na ideia de "carência" e de "inadequação" dos trabalhadores as funções que realizam, essa lógica mobiliza o discurso da importância e da necessidade da formação como condição de aquisição de competências técnicas para a melhoria do desempenho individual e do aumento da produtividade. Porém, ao acentuar a dimensão técnica e individual, ignora na mesma medida a dimensão relacional e colectiva das situações de trabalho e dos processos de formação, sendo essas, afinal, aquelas que mais caracterizam a actividade socioeducativa: o trabalho em equipas de alunos e professores; a interformação, ou formação entre pares; as parcerias entre professores e outros actores educativos locais.

Subordinado a uma lógica individual e instrumental e ao formalismo que decorrem da ligação à progressão na carreira, o sistema de formação contínua não tem sido propício, em suma, ao desenvolvimento de processos colectivos de aprendizagem referenciados aos contextos vivenciais. No entanto, as abordagens que mais têm contribuído para a problematização do campo da formação profissional contínua e para a enunciação de alternativas à racionalização e instrumentalidade que o têm caracterizado têm provindo de reflexões que relevam sobretudo as dimensões formativas dos contextos e das situações de trabalho (Correia, 1996). A seguir enunciaremos algumas dessas alternativas que, embora acentuando diferentes aspectos, propõem em comum uma concepção da formação contínua como educação de adultos.
Por exemplo, a possibilidade de o campo da formação integrar o informal e o relacionar com o formal, explorando as "sinergias entre educação formal, não formal e informal" (Pain, 1990, p. 227) constitui uma dimensão central desse debate alternativo. A valorização da informalidade permite ultrapassar as preocupações quase exclusivas com o ensino, os programas e os conteúdos - conceitos associados à racionalidade escolar que tem dominado o campo da formação de adultos - e orientar os processos formativos com base na aprendizagem e na experiência.

Ao integrar os saberes experienciais do ofício, as dimensões informais constituem-se como uma condição de passagem de uma concepção de formação como mero programa formal para uma concepção de formação como dispositivo. O conceito de dispositivo de formação remete para uma dimensão de temporalidade, em que se privilegia a longa duração, e para uma dimensão de territorialidade, em que se sobrepõem um espaço-trabalho e um espaço-formação (Canário, 1994). Essa concepção mais fluida da formação, entendida mais como bricolage do que como engenharia, pode constituir uma possibilidade de superação da concepção burocrático-industrial arreigada ao campo da formação dos adultos e, em particular, ao actual sistema de formação contínua de professores.

Essas conceptualizações procuram aproximar e interpelar a formação e a acção, tradicionalmente dissociadas por uma concepção que separa os tempos e os espaços de transmissão e aquisição de saberes - a formação - dos tempos e espaços da sua aplicação o trabalho -, sendo este encarado como o campo da mera aplicação desses saberes. O reconhecimento da importância do informal permite considerar as formas não intencionais da formação, as dimensões formativas da organização e da acção, os "efeitos formativos do quotidiano" (Pain, 1990). Assim, ao permitir analisar as "faces ocultas da formação" (Dominicé, 1990, p. 11), essas abordagens dão um contributo importante para a deslocação do objecto praxeológico da formação, passando de uma concepção da formação de adultos trabalhada à semelhança do modelo escolar para uma concepção trabalhada como "dinâmica de 
formatividade" (Correia, 1992). Tal deslocação implica, todavia, uma mudança de registo. Implica passar de uma lógica de sistema e de programa, que separa os lugares e os tempos da cidadania, do trabalho e da formação, para uma lógica de dispositivo de formação e de dinâmica de formatividade, que une esses tempos e lugares num processo único e permanente.

Essas abordagens valorizam essencialmente as dimensões da autoformação e da interformação; da "ecoformação e da co-formação" (Pineau, 1989). Pondo em destaque as dimensões da experiência e da biografia dos sujeitos em formação, procuram deslocar o registo da oferta e do consumo acrítico e instrumental da formação para um registo de produção reflexiva e emancipatória de formação. Dentro dessa abordagem biográfica, podem referir-se os trabalhos de Nóvoa e Finger (1988), Pineau e Jobert (1989), Josso (1990) e Dominicé (1990). Nessa mesma perspectiva, acentuando a concepção da formação de adultos como formação experiencial, podem referir-se ainda outros trabalhos de Courtois e Pineau (1991) e de Jarvis (1995). Essas conceptualizações incorporam uma visão mais fluida dos processos formativos, cujo modo de apropriação é a própria acção colectiva, por meio da implicação e da "impregnação" (Pain, 1990, p. 161). Assim, a formação é entendida como "um processo apropriativo de oportunidades educativas, vividas no quotidiano" (Canário, 1994, p. 32).

Conferindo centralidade aos fenómenos inconscientes e do imaginário, a abordagem psicanalítica dá também um contributo importante para a superação da lógica racional-formal, que incorpora apenas os aspectos materiais e intencionais. Essa abordagem introduz no campo da formação uma conceptualização que sublinha sobretudo a importância do simbolismo do dispositivo analítico, considerando esse simbolismo tão ou mais importante que a materialidade do formador. Os trabalhos de Natanson (1994) e de Alin (1996) são exemplos da pertinência da incorporação dessas dimensões simbólicas e subjectivas na formação. Christian Alin considera que a escuta das subjectividades é uma componente essencial dos processos formativos, pelo facto de muitos de nós, professores, formadores, cuja actividade é dizer, falar, não nos entendermos, não nos escutarmos. Tanto mais que, como afirma Madeline Natanson, os indivíduos em formação têm o direito de queixarem-se e desabafarem, pelo que a formação constitui um dispositivo de libertação dessas angústias e do stress profissional que marcam fortemente a actividade dos professores na actualidade.

Nesta breve análise da literatura não se pretende definir categorias exaustivas. Isso não seria possível num campo de grande transversalidade como é a formação. As abordagens que têm sido produzidas em torno dessa problemática relacionam várias dimensões, como a formação, o emprego, o trabalho, a socialização e identidades profissionais. No entanto, há ênfases diferentes, como já foi salientado. É o caso das conceptualizações que enfatizam as potencialidades da aprendizagem realizada através da organização e pela própria organização (Barroso, 1997; Bolívar, 1997). O projecto e as situações participativas de trabalho são as que proporcionam mais oportunidades de formação. Mas, como lembra João Barroso (1997, p. 75),

\footnotetext{
[...] para que seja possível pôr em prática modalidades de formação que permitam aos trabalhadores aprenderem através da organização e das suas situações de trabalho, é preciso que a própria organização "aprenda" a valorizar a experiência dos trabalhadores e a criar condições para que eles participem na tomada de decisão.
}

O conceito de aprendizagem organizacional procura, assim, traduzir a ideia de que a formação e a mudança se operam pela organização, não se tratando, portanto, de mudar pessoas supostamente carentes, mas as organizações e os seus problemas, valorizandose os saberes experienciais e os contextos e processos colectivos de trabalho.

Outras conceptualizações têm incidido sobretudo nas questões pedagógicas da formação. Como considera Silva, "a educação de adultos pode radicar a sua mais distintiva contribuição [às questões educativas e sociais] numa afirmação de método, em sentido amplo - o modo de formação dirigido à autonomia e à participação dos sujeitos em formação" (Silva, 1990, 
p. 97). Assim, importa reflectir sobre as práticas de formação de adultos e sobre os métodos utilizados. De acordo com Ferry (1987), podemos definir três modelos de práticas de formação: o modelo centrado nas aquisições, o modelo centrado nos processos e o modelo centrado na análise.

O modelo centrado nas aquisições pressupõe que a prática é a mera aplicação da formação (teoria); o modelo centrado nos processos valoriza essencialmente as experiências dos indivíduos em formação, situando a teorização ao nível da formalização das práticas; o modelo centrado na análise considera que os indivíduos se formam por um trabalho sobre si mesmos, articulando teoria e prática. Com efeito, a prática por si só não é formadora; ela pode tornar-se objecto de análise, de reflexão e compreensão com a ajuda de um referencial teórico. Por sua vez, Lesne (1984) define três "modos de trabalho pedagógico". O tipo "transmissivo de orientação normativa" assenta numa relação pedagógica hierarquizada entre formador e formando, sendo a pessoa em formação considerada essencialmente objecto de socialização; o tipo "incitativo de orientação pessoal" valoriza as dimensões interpessoais e individuais e assenta em relações pedagógicas horizontais, sendo a pessoa sujeito da sua própria formação e socialização; o tipo "apropriativo centrado na inserção social do indivíduo" assenta no exercício democrático do poder pelas pessoas em formação e tem como objectivo desenvolver a capacidade de agirem de forma que modifiquem as próprias condições sociais, pedagógicas e organizacionais da sua actividade. Nesse último caso, a pessoa em formação é considerada agente de socialização, com capacidade para transformar-se e transformar a sociedade em que vive.

Podemos referir, finalmente, um conjunto de abordagens que procuram alargar a problemática da formação de adultos às dimensões sociais e comunitárias, que inter-relacionam os temas da formação com o desenvolvimento social (Silva, 1990; Melo, 1994; Amaro, 1994), com as redes (Castéran, 1988) e as parcerias (Mérini, 1996; Zay, 1994); que transformam a relação entre a escola e a comunidade no elemento mediador da formação (D’Espiney \& Canário, 1994); que defendem perspectivas inter/multiculturais na formação de professores (Stoer, 1992; Cortesão \& Stoer, 1997). Ainda nessas concepções sociocomunitárias da formação, incluem-se os trabalhos de Zeichner (1993) e de Liston e Zeichner (1993), que salientam a formação centrada na escola e na comunidade. Embora incidindo principalmente no campo da formação inicial de professores, esses trabalhos dão contributos importantes para a formação contínua, chamando a atenção para as questões comunitárias da formação e para a necessidade de ela ter em conta as condições sociais em que se realiza a acção educativa. A formação pode contribuir, assim, para a "participação comunitária" (Freire, 1996) e para a "construção da cidadania democrática" (Lima, 1996), numa linha em que a formação dos adultos - e a formação contínua de professores, de um modo particular - se articula intimamente com as problemáticas da justiça social, da diversidade cultural, da organização democrática da escola, da participação e da cidadania das crianças e dos jovens - questões que se colocam hoje com grande intensidade na actividade educativa.

\section{Conclusão}

Nas últimas três décadas, as escolas e os professores têm estado envolvidos num ambiente de reforma permanente. Os temas das reformas educativas - a formação contínua obrigatória para progressão na carreira, a autonomia e gestão da escola, a reorganização curricular etc. - têm gerado, no seio dos professores, a ideia de que as mudanças lhes são exteriores ou de que lhes compete apenas o papel de actores secundários. Tem-se difundido, igualmente, a ideia de que as mudanças da educação e da escola passam essencialmente pela gestão, gerando-se, em consequência, a ilusão de que se trata de fenómenos da exclusiva responsabilidade dos administradores e gestores, em relação aos quais os professores que trabalham quotidianamente com os alunos são, ou sentem-se, alheios.

A ideia de que as "boas práticas" são as práticas de gestão povoa hoje o imaginário docente. Mesmo 
falando-se muito em autonomia, é a vertente gestionária que tem estado no centro das preocupações das escolas e dos agrupamentos de escolas, designadamente com a instalação de órgãos, a realização de reuniões e a elaboração de documentos escritos. Ora, as lógicas das reformas educativas e a ideia a elas associada de que a essência da actividade educativa é a gestão, tendencialmente vinculada a uma concepção burocrática, têm produzido diversos efeitos ao nível das subjectividades dos professores. Um dos principais efeitos é, como se disse, gerar ou acentuar o sentimento de que as mudanças na esfera da acção pedagógica lhes são exteriores. $\mathrm{O}$ ambiente de reforma permanente em que as escolas têm estado mergulhadas tem sido, assim, mais favorável à emergência de um pensamento fatalista e resignado do que à acção autónoma e reflexiva. A retórica da eficiência, da eficácia, da qualidade, da excelência etc. é apelativa, criando nas escolas e entre os professores uma "azáfama de mudança", mas não lhes deixando tempo para a reflexão sobre o que é necessário realmente mudar. Como sustenta J. A. Correia (2000), a "escola atarefada" perde, desse modo, sua capacidade de formular perguntas e definir problemáticas; e, ao mesmo tempo que afirma ter-se libertado do peso da burocracia estatal para se tornar ágil, leve e flexível, parece também se ter libertado do peso das suas convicções e dos seus princípios. Tratase, como diz Correia, de um excesso de activismo incontrolado e conformado e um défice de reflexividade e inconformidade.

Com as políticas ditas de descentralização, autonomia e gestão local da escola, os responsáveis do Ministério da Educação passaram a dispor de mais "tempo livre" para invadir as escolas com as suas "propostas" de inovação, criando nos contextos da acção local um verdadeiro corrupio. Os professores têm sido obrigados a elaborar o "projecto educativo de escola", o "projecto curricular de escola", o "projecto curricular de turma" e outros, mas em grande medida assumindo essa obrigação como um trabalho administrativo de elaboração de documentos escritos exigidos pela administração e pela inspecção. Nesse contexto das reformas educativas, o "projecto" trans- formou-se numa espécie de palavra mágica. Porém, como sustenta criticamente Nicolas-Le Strat (1996), a forma-projecto pretende "domesticar o futuro", multiplicando os momentos em que a vida se subordina ao cerimonial da formalização projectiva, em detrimento de outros princípios de acção, designadamente dos que se desenvolvem de modo menos linear, intencional e estratégico e que não se sujeitam imediatamente aos imperativos da racionalidade instrumental. A permanente intencionalidade do "projecto", principalmente quando ele é entendido numa lógica burocrática, como um mero documento escrito, retira à experiência de cada um a aventura, a deriva, as hesitações e as transgressões que configuram a autenticidade.

Com efeito, os aspectos formais e morfológicos de composição dos órgãos de gestão das escolas e agrupamentos de escolas, das reuniões, dos documentos que têm de elaborar, quer no nível da escola e do agrupamento quer individualmente, invadiram as preocupações dos professores, em detrimento dos assuntos respeitantes às actividades, aos saberes e às aprendizagens dos alunos. O clima de reforma permanente não tem sido, portanto, favorável à reflexão, à experimentação e à descoberta de alternativas pedagógicas, na medida em que a "azáfama de mudança" e o "alvoroço projectocrático" que envolvem as escolas e os professores têm gerado uma mentalidade expectante e uma lógica de sobrevivência que se traduz numa maior preocupação com a encenação, o aparato e o faz-de-conta do que com os processos educativos concretos. Tal clima não tem deixado tempo para a reflexão sobre questões que possam fazer a própria agenda educativa das escolas e dos actores locais. Estes andam cada vez mais atarefados, desinteressando-se ou vendo-se impossibilitados, muitas vezes, de exercer uma atitude reflexiva e crítica sobre os constrangimentos e as oportunidades da sua acção profissional. Os "temas do momento" das reformas educativas tendem a ser encarados numa lógica cumulativa (mais disciplinas, mais documentos, mais reuniões etc.) e numa lógica de exterioridade relativamente aos processos de mudança, e não como uma possibilidade de transformação do trabalho quotidiano que desenvolvem com os alunos. 
Em suma, as ideias de descentralização e de modernização que têm pautado o discurso em torno das reformas educativas impregnaram as subjectividades dos professores, misturando-se com uma mentalidade centralista e burocrática que se mantém fortemente enraizada. Ora, essa mistura tem causado uma espécie de esquizofrenia organizacional e profissional: a ideia de mudança surge associada aos valores da produtividade, competitividade, qualidade etc., mas os professores, os gestores escolares e outros actores educativos continuam a agir em moldes centralistas e burocráticos. Nesse cenário, tem-se difundido a crença de que as "boas práticas" dos professores - assim como a sua produtividade e competitividade, ou, por outras palavras, o seu desempenho - são aferidas a partir da "qualidade" dos documentos que elaboram, como os referidos anteriormente, e não tanto a partir do trabalho que desenvolvem quotidianamente com os alunos. É, no entanto, pelo questionamento e pela superação dessas lógicas instaladas, concebendo a formação contínua de professores como educação de adultos e, como tal, assente em princípios participativos, democráticos e emancipatórios, na sua dupla dimensão individual e colectiva, que podem ser resgatados o sentido e a utilidade da formação para a acção educativa.

\section{Referências bibliográficas}

AFONSO, Almerindo J. Políticas educativas e avaliação educacional. Braga: IEP/CEEP/Universidade do Minho, 1998.

ALIN, Christian. Etre formateur: quand dire c'est écouter. Paris: l'Harmattan, 1996.

AMARO, Rogério R. Formar para des-envolver. Formar, n. 12, p. 6-12, ago./out. 1994.

BALL, Stephen J. Education reform: a critical and post-structural approach. Buckingham: Open University Press, 1994.

Reformar escolas/reformar professores e os terrores da performatividade. In: ESTÊVÃO, Carlos Vilar; AFONSO, Almerindo J.; LIMA, Licínio C. (Orgs.). Política e administração da educação: investigação, formação e práticas. In: CONGRESSO LUSO-BRASILEIRO, 2., Braga, 2001. Actas... Braga: CIED Universidade do Minho, 2002. p. 9-20.
; VAN ZANTEN, Agnès. Logiques de marché et éthiques contextualisées dans les systèmes français et britanique. Éducation et Sociétés, n. 1, p. 47-71, 1998.

BARROSO, João. Formação, projecto e desenvolvimento organizacional. In: CANÁRIO, Rui (Org.). Formação e situações de trabalho. Porto: Porto, 1997. p. 61-76.

BOLÍVAR, António. A escola como organização que aprende. In: CANÁRIO, Rui (Org.). Formação e situações de trabalho. Porto: Porto, 1997. p. 79-100.

. Centros de formação das associações de escolas: Que futuro? In: AMIGUINHO, Abílio; CANÁRIO, Rui (Orgs.). Escolas e mudança: o papel dos centros de formação. Lisboa: Educa, 1994. p. 13-58.

. Inovação educativa e práticas profissionais reflexivas.

In: CANÁRIO, Rui; SANTOS, Irene (Orgs.). Educação, inovação e local. Setúbal: ICE, 2002. p. 13-23.

CASTÉRAN, Marie-Françoise. Le fonctionnement en réseaux dans la formation continue des enseignants du second degré. Education Permanente, v. 4, n. 96, p. 49-60, 1988.

CORREIA, J. Alberto. Dispositivos e disposições na formação de adultos: a dinâmica da formatividade. In: CONGRESSO DA SOCIEDADE PORTUGUESA DE CIÊNCIAS DA EDUCAÇÃO,

2., Braga, 1992. Anais... Braga: Sociedade Portuguesa de Ciências da Educação, 1992. Policopiado.

. Formação e trabalho: contributos para uma transformação dos modos de os pensar na sua articulação. In: ESTRELA, Albano; CANÁRIO, Rui; FERREIRA, Júlia (Eds.). Formação, saberes profissionais e situações de trabalho. Lisboa: Afirse, 1996. p. 3-30.

As ideologias educativas em Portugal nos últimos 25 anos. Porto: Asa, 2000.

CORTESÃO, Luísa; STOER, R. Stephen. Investigação-acção e a produção de conhecimento no âmbito de uma formação de professores para a educação inter/multicultural. Educação, Sociedade \& Culturas, n. 7, p. 7-28, 1997.

COURTOIS, Bernadette; PINEAU, Gaston (Coords.). La formation expérentielle des adultes. Paris: La Documentation Française, 1991.

D’ESPINEY, Rui; CANÁRIO, Rui (Orgs.). Uma escola em mudança com a comunidade. Projecto ECO, 1986-1992. Experiências e reflexões. Lisboa: Instituto de Inovação Educacional, 1994.

DOMINICÉ, Pierre. L'Histoire de vie comme processus de formation. Paris: L'Harmattan, 1990. 
FERREIRA, Fernando Ilídio. Dinâmicas locais de formação. Braga: CESC/Universidade do Minho, 1998.

. O local em educação. Animação, gestão e parceria.

Lisboa: Fundação Calouste Gulbenkian, 2005.

FERRY, Gilles. Le trajet de la formation. Paris: Dunod, 1987.

FORMOSINHO, João. A universidade e a formação de educadores de infância: potencialidades e dilemas. In: MACHADO, Lucia A. (Org.). Encontros e desencontros em educação infantil. São Paulo: Cortez, 2002. p. 169-188.

FREIRE, Paulo. Educação e participação comunitária. Inovação, v. 9, n. 3, p. 305-312, 1996.

JARVIS, Peter. O processo de aprendizagem e a modernidade tardia. Revista Portuguesa de Educação, v. 8, n. 2, p. 1-14, 1995.

JOBERT, Bruno. Le tournant néo-libéral en Europe. Paris: L'Harmattan, 1994.

JOSSO, Christine. Le sujet en formation. Lausanne: L'agge d'Homme, 1990.

LESNE, Marcel. Trabalho pedagógico e formação de adultos. Lisboa: Fundação Calouste Gulbenkian, 1984.

LIMA, Licínio C. Educação de adultos e construção da cidadania democrática: para uma crítica do gerencialismo e da educação contábil. Inovação, v. 9, n. 3, p. 283-297, 1996.

; AFONSO, Almerindo J. Reformas da educação pública. Democratização, modernização, neoliberalismo. Porto: Afrontamento, 2002.

LISTON, Daniel P.; ZEICHNER, Kenneth M. Formación del profesorado y condiciones sociales de la escolarización. Madrid: Morata, 1993.

MELO, Alberto. Educação e formação para o desenvolvimento rural. In: LIMA, Licínio C. (Org.). Educação de adultos. Forum I. Braga: Universidade do Minho, 1994. p. 137-149.

MÉRINI, Corinne. Le partenariat en formation: espace d'interculturalité. In: ESTRELA, Albano; CANÁRIO, Rui; FERREIRA, Júlia (Eds.). Formação, saberes profissionais e situações de trabalho. Lisboa: Afirse, 1996. p. 411-428.

MEYER, John W. Globalização e currículo. Problemas para a teoria em sociologia da educação. In: NÓVOA, António; SCHRIEWER, Jürgen (Eds.). A difusão mundial da escola. Lisboa: Educa, 2000. p. 15-32.

NATANSON, Madeline. Des lieux pour se plaindre. Une écoute psychanalitique dans la formation. Paris: Matrice, 1994.

NICOLAS-LE STRAT, Pascal. L'Implication. Une nouvelle base de l'intervention social. Paris: L'Harmattan, 1996.
NÓVOA, António. Os professores na virada do milénio: do excesso dos discursos à pobreza das práticas. Educação e Pesquisa, v. 25, n. 1, p. 11-20, jan./jun. 1999.

.; FINGER, Matthias (Orgs.). O método (auto)biográfico e a formação. Lisboa: Ministério da Saúde, 1988. OGIEN, Albert. L'esprit gestionnaire. Une analyse de l'air do temps. Paris: Éditions de l'École des Hautes Etudes Sociales, 1995.

PAIN, Abraham. Education informelle. Les effets formateurs dans le quotidien. Paris: L'Harmattan, 1990.

PINEAU, Gaston. La formation expérientielle en auto, eco et coformation. Education Permanente, v. 4, n. 100/101, p. 23-30, 1989. .; JOBERT, Guy (Coords.). Histoires de vie. Utilisation pour la formation. Paris: L'Harmattan, 1989.

POPKEWITZ, Thomas S. O Estado e a administração da liberdade nos finais do século XX: descentralização e distinções Estado/ Sociedade civil. In: SARMENTO, Manuel (Org.). Autonomia da escola. Políticas e práticas. Porto: Asa, 2000. p. 11-66.

SARMENTO, Manuel. Escola básica: sinais de abril em tempo descontínuo. Revista Portuguesa de Educação, v. 12, n. 1, p. 149$169,1999$.

SILVA, Augusto Santos. Educação de adultos. Educação para o desenvolvimento. Porto: Edições Asa, 1990.

STOER, R. Stephen. A reforma educativa e a formação inicial e contínua de professores em Portugal: perspectivas inter/multiculturais. In: NÓVOA, António; POPKEWITZ, Thomas S. (Orgs.). Reformas educativas e formação de professores. Lisboa: Educa, 1992. p. 71-81.

WHITTY, Geoff. Autonomia da escola e escolha parental: direitos do consumidor versus direitos do cidadão na política educativa contemporânea. Educação, Sociedade \& Culturas, n. 6, p. 117$141,1996$.

ZAY, Danielle (Dir.). La formation des enseignants au partenariat. Une réponse à la demamde sociale? Paris: PUF, 1994.

ZEICHNER, Kenneth M. A formação reflexiva de professores. Ideias e práticas. Lisboa: Educa, 1993.

$$
\text { Legislação }
$$

Lei n. 46/86, de 14 de outubro - Lei de Bases do Sistema Educativo.

Decreto-lei n. 344/89, de 11 de outubro - Ordenamento Jurídico da Formação dos Educadores de Infância e dos Professores dos Ensinos Básico e Secundário. 
Decreto-lei n. 139-a/90, de 28 de abril - Estatuto da Carreira dos Educadores de Infância e dos Professores do Ensino Básico e Secundário.

Decreto-lei n. 249/92, de 9 de novembro - Regime Jurídico da Formação Contínua de Professores.

FERNANDO ILÍDIO FERREIRA, doutor em estudos da criança pela Universidade do Minho, é professor do Instituto de Estudos da Criança da mesma Universidade. Actua no projecto: "Ensino superior, formação e desenvolvimento profissional", Centro de Investigação em Formação de Profissionais de Educação da Criança, da Universidade do Minho (Unidade de I\&D da Fundação para a Ciência e Tecnologia). Publicações recentes: $O$ local em educação: animação, gestão e parceria (Lisboa: Fundação Calouste Gulbenkian, 2005); em co-autoria com FORMOSINHO, João;
FERNANDES, António Sousa; MACHADO, Joaquim. Administração da educação. Lógicas burocráticas e lógicas de mediação (Porto: Asa, 2005); "Modos de governo da educação: políticas, actores e conexões. Administração educacional" (Revista do Fórum Português de Administração Educacional, n. 6, p. 19-27, 2006); em co-autoria com OLIVEIRA, Joaquim Marques. "Escola e políticas educativas: lugares incertos da criança e da cidadania. (Perspectiva - Revista do Centro de Ciências da Educação, Florianópolis: Universidade Federal de Santa Catarina, v. 25, n. 1, p. 127-148, jan./jun. 2007). Projectos de investigação em curso: "TISSNTE Project - Teacher induction: supporting the supporters of novice teachers in Europe" (www.tissnte.eu).E-mail: filidio@iec.uminho.pt

Recebido em outubro de 2007

Aprovado em janeiro de 2008 
teve equivalente na transformação das concepções e práticas de formação, gerando até lógicas contrárias aos princípios participativos e emancipatórios da educação de adultos. A formação desenvolveu-se predominantemente à imagem do modelo formal e académico da escolarização e com influências de políticas de racionalização das reformas educativas. Nas primeiras secções do artigo, abordam-se essas lógicas, salientando-se seus efeitos nas subjectividades dos professores. Em seguida, abordam-se concepções alternativas, considerando a formação contínua numa perspectiva de educação de adultos e pressupondo, assim, outro tipo de relação dos professores com a formação.

Palavras-chave: reformas educativas; formação de professores; subjectividades

\section{Educational reforms, training and} teacher subjectivities

In the context of the educational reforms initiated in Portugal in the 1980s, the in-service training of teachers experienced a significant increase, associated both with strong financial backing from the European Union and a logic of supply and demand induced by a legal framework which established a link between training and career progression. This article defends the position that this increase found no equivalence in the transformation of conceptions

Fernando Ilídio Ferreira

\section{Reformas educativas, formação e subjectividades dos professores}

No contexto das reformas educativas iniciadas em Portugal nos anos de 1980 , a formação contínua de professores teve forte incremento, associado a financiamentos avultados da União Européia e a uma lógica de oferta e procura induzida por um enquadramento legal que estabeleceu uma ligação entre a formação e a progressão na carreira. Neste artigo, defende-se que esse incremento não and practices of training, and even generated an opposing logic to the participatory and emancipatory principles of adult education. Teacher training has predominantly developed as a reflection of the formal and academic model of schooling and influenced by policies of rationalization of educational reforms. In the first sections of this article, the effects of these logics on teacher subjectivities are analysed. Later, alternative conceptions of training are dealt with, considering in-service teacher training 
in a perspective of adult education and presupposing, in this way, a different relationship between teachers and training.

Key words: educational reforms; teacher training; subjectivities

\section{Reformas educativas, formación y} subjetividades de los profesores

En el contexto de las reformas educativas iniciadas en Portugal en los años de 1980, la formación continua de profesores tuvo un fuerte incremento, asociado a financiamientos de gran porte de la Unión Europea y a una lógica de oferta y procura inducida por un encuadramiento legal que estableció una unión entre la formación y la progresión en la carrera. En este artículo, se defiende que ese incremento no tuvo equivalente en la transformación de las concepciones y prácticas de formación, generando lógicas hasta contrarias a los principios participativos y de emancipación de la educación de adultos. La formación se desarrolló predominantemente a la imagen del modelo formal y académico de la escolarización y con influencias de políticas de racionalización de las reformas educativas. En las primeras secciones del artículo, se abordan esas lógicas, acentuándose sus defectos en las subjetividades de los profesores. En seguida, se abordan concepciones alternativas, considerando la formación continua en una perspectiva de educación de adultos y previendo, así, otro tipo de relación de los profesores con la formación.

Palabras clave: reformas educativas; formación de profesores; subjetividades 